\title{
Further evidence of human silica nephrotoxicity in occupationally exposed workers
}

\author{
Tze Pin Ng, Hock Siang Lee, Wai Hoong Phoon
}

\begin{abstract}
It has previously been shown that granite workers with heavy exposure to silica had glomerular and proximal tubular dysfunction evidenced by increased urinary excretions of albumin, $\alpha$-1-microglobulin (AMG), and $\beta-N-$ acetyl-glucosaminidase (NAG). The investigation was replicated in another group of granite workers to further elucidate the exposure effect relation. The urinary excretion of albumin, $\alpha$-1-microglobulin (AMG), $\beta-2-$ microglobulin (BMG), and $\beta$-N-acetylglucosaminidase (NAG) was determined in two groups of granite workers with low and high exposure to silica. Low molecular weight proteinuria and enzymuria were significantly correlated with duration of exposure in the high but not the low exposure group. These increases were most pronounced in those with 10 or more years of heavy exposure, and in those with radiological evidence of pulmonary fibrosis, particularly those with rounded small opacities denoting classical silicosis. These results provide further evidence that prolonged and heavy exposure to silica is associated with nephrotoxic effects in granite workers.
\end{abstract}

(British Fournal of Industrial Medicine 1993;50:907-912).

The evidence that silica is nephrotoxic in occupationally exposed persons is limited. Anecdotal reports and uncontrolled studies of clinical and pathological case series suggest that severe pulmonary silicosis, especially acute silicosis, is associated with glomerulotubular disease. ${ }^{1-8}$ We have also reported preliminary findings from a recent cross

Department of Community, Occupational, and Family Medicine, National University of Singapore T P Ng

Department of Industrial Health, Ministry of Labour, Singapore

H S Lee, W H Phoon sectional study of an increased urinary excretion of albumin, $\alpha-1$-microglobulin (AMG), and $\beta-N-$ acetyl-glucosaminidase (NAG) in granite workers with high exposure to silica compared with healthy unexposed subjects. ${ }^{9}$ Some of these alterations in renal function, particularly for albumin and NAG, were apparently greater and persistent in silicotic subjects who were assumed to have had greater exposure to dust and who had not been exposed to silica for many years. We have replicated the study in another larger group of granite workers, with the further aim of elucidating the exposure-effect relation between the urinary alterations on the one hand and the intensity and duration of exposure to silica on the other.

\section{Materials and methods}

The study subjects were selected from among a total of 159 workers in three granite quarries (not covered in the previous study), who held jobs with differing intensities of exposure to dust. A high dust exposure group of workers included those who were employed regularly in rock drilling and rock crushing jobs for at least a year; whereas a low exposure group included the rest of the workers who were mostly employed in equipment and vehicle maintenance and servicing work in the workshops, as loader operators and dumper truck drivers, and other administrative workers (clerks, office assistants, storemen etc). The exclusion criteria were a known history of glomerulonephritis, urinary calculi, or other renal diseases or diabetes, hypertension, or regular recent ingestion of analgesics. A total of 21 subjects was excluded in this way, and from among the rest of the workers who provided suitable specimens of urine (see later), a random one in two sample of 67 subjects was eventually studied.

Samples of urine were collected from the subjects in the morning from 10.00 am to 12.00 noon. The $\mathrm{pH}$ was determined immediately after collection and all samples for BMG estimations were neutralised immediately with a standard buffered solution. The samples were stored frozen and analysed within one month of collection. Urinary 
Table 1 Basic characteristics and urinary indices by exposure group

\begin{tabular}{|c|c|c|c|}
\hline & Low exposure & High exposure & p Value \\
\hline $\begin{array}{l}\text { No } \\
\text { Race. }\end{array}$ & 31 & 36 & \\
\hline \multicolumn{4}{|l|}{ Race: } \\
\hline Chinese (\%) & $26(83 \cdot 9)$ & $34(94 \cdot 4)$ & \\
\hline Matays (\%) & $4(12 \cdot 9)$ & $2(5 \cdot 6)$ & \\
\hline Indians (\%) & $1(3 \cdot 2)$ & $0(0.0)$ & NS \\
\hline Age (y) & $32 \cdot 8(6 \cdot 2)$ & $36 \cdot 6(11 \cdot 1)$ & NS \\
\hline Years employed & $8 \cdot 6(5 \cdot 1)$ & $12 \cdot 5(10 \cdot 2)$ & 0.049 \\
\hline \multicolumn{4}{|l|}{ Current smokers: } \\
\hline No $(\%)$ & $10(32 \cdot 3)$ & $17(47 \cdot 2)$ & \\
\hline Cigarette-years & $195(172)$ & $309(324)$ & NS \\
\hline \multicolumn{4}{|l|}{ Ex-smokers: } \\
\hline No $(\%)$ & $7(22 \cdot 6)$ & $4(11 \cdot 1)$ & \\
\hline Cigarette-years & $133(162)$ & $287(151)$ & NS \\
\hline Urinary creatinine $(\mathrm{g} / \mathrm{l})$ & $1.58(0.82)$ & $1.45(0.65)$ & NS \\
\hline Urinary AMG (mg/g creatinine) & $3 \cdot 10(2 \cdot 00)$ & $5.46(3.05)$ & 0.0003 \\
\hline Urinary BMG (mg/g creatinine GM (GSD)) & $61.6(1.86)$ & $89 \cdot 1(2 \cdot 19)$ & 0.038 \\
\hline (Range) & $(5 \cdot 3-376 \cdot 4)$ & $(10 \cdot 9-987 \cdot 8)$ & \\
\hline Urinary albumin (mg/g creatinine) & $5 \cdot 83(3 \cdot 23)$ & $6.46(3 \cdot 29)$ & NS \\
\hline Urinary NAG (U/g creatinine) & $1.56(0.81)$ & $2 \cdot 26(1 \cdot 72)$ & 0.034 \\
\hline
\end{tabular}

Values are mean (SD) unless stated otherwise; GM, geometric mean; GSD, geometric standard deviation.

albumin was measured with an immunoprecipitation assay kit (Orion Diagnostica, Finland), AMG and BMG were analysed with enzyme-immunoassay kits (Fujirebio Inc, Japan), and NAG was analysed with a colorimetric assay (BoehringerMannheim, Germany). Urinary concentrations of these substances were corrected for urinary creatinine. Samples with $\mathrm{pH}$ below 5.5 and urinary creatinine below $0.3 \mathrm{~g} / 1$ were excluded.

At the same time large sized chest radiographs of all the workers were taken and the films were read by three experienced physician readers, independently and in random order, without knowledge of the workers' personal and exposure particulars. The results of these radiographic readings have been reported in another paper, ${ }^{10}$ and the majority readings of the three readers were used to classify each of the 67 subjects in this study as being pneumoconiotic or non-pneumoconiotic. Radiological pneumoconiosis was defined as rounded or irregular small opacities equal to or greater than $1 / 0$.
Logarithmic transformation was used to normalise the distribution of values for $B M G$, and Student's $t$ test and $\chi^{2}$ tests of significance were used as appropriate. A p value $<0.05$ was considered significant.

\section{Results}

The men in the high exposure group (drilling and crusher workers) did not differ significantly from the men in the low exposure group (maintenance, transport, and administrative workers) in respect of age, race, and smoking habits (table 1). There was no significant relation of these variables with any of the urinary indices of renal function. The urinary creatinine concentrations in both groups were similar, but the concentrations of $A M G, B M G$, and NAG, corrected for creatinine, were significantly higher in the high exposure group. The concentration of albumin, was, however, not significantly increased in the high exposure group.

Table 2 Correlation coefficients ( $r$ ) of exposure and urinary indices by exposure group

\begin{tabular}{|c|c|c|c|c|c|}
\hline \multirow[b]{2}{*}{ Indices } & & \multicolumn{2}{|c|}{ Low exposure } & \multicolumn{2}{|c|}{ High exposure } \\
\hline & & $r$ & p Value & $r$ & p Value \\
\hline \multirow[t]{5}{*}{ Age } & Job-years & 0.58 & 0.001 & 0.71 & 0.0001 \\
\hline & $\mathrm{AMG}$ & -0.01 & & $0 \cdot 27$ & \\
\hline & Log BMG & -0.03 & NS & $0 \cdot 15$ & \\
\hline & NAG & $0 \cdot 24$ & NS & 0.52 & 0.0011 \\
\hline & ALB & $0 \cdot 19$ & NS & $-0 \cdot 01$ & NS \\
\hline \multirow[t]{4}{*}{ Job-years } & AMG & 0.01 & NS & 0.33 & 0.047 \\
\hline & Log U BMG & $-0 \cdot 10$ & NS & 0.40 & 0.015 \\
\hline & NAG & 0.23 & NS & 0.55 & 0.0005 \\
\hline & ALB & $0 \cdot 24$ & NS & -0.03 & NS \\
\hline \multirow[t]{3}{*}{ AMG } & $\log B M G$ & 0.36 & 0.048 & 0.64 & 0.0001 \\
\hline & ALB & -0.21 & NS & 0.05 & NS \\
\hline & NAG & $0 \cdot 24$ & NS & 0.50 & 0.019 \\
\hline \multirow[t]{2}{*}{ Log BMG } & ALB & $0 \cdot 24$ & NS & $0 \cdot 18$ & NS \\
\hline & NAG & 0.39 & 0.03 & 0.46 & 0.005 \\
\hline ALB & NAG & $0 \cdot 21$ & NS & -0.13 & NS \\
\hline
\end{tabular}

Values of AMG, BMG, and NAG measured in urine. 
Table 3 Urinary indices by exposure groups and duration of exposure

\begin{tabular}{|c|c|c|c|}
\hline & \multirow[b]{2}{*}{ Low exposure } & \multicolumn{2}{|l|}{ High exposure } \\
\hline & & $<10 y r$ & $\geqslant 10 y r$ \\
\hline $\begin{array}{l}\text { No } \\
\text { Urinary AMG (mg/g creatinine) } \\
\text { Urinary BMG (mg/g creatinine; GM (GSD)) } \\
\text { (Range) } \\
\text { Urinary Alb (mg/g creatinine) } \\
\text { Urinary NAG (U/g creatinine) }\end{array}$ & $\begin{array}{l}31 \\
3 \cdot 10(2 \cdot 00) \\
61 \cdot 6(1 \cdot 86) \\
(5 \cdot 3-376 \cdot 4) \\
5 \cdot 83(3 \cdot 23) \\
1.56(0.81)\end{array}$ & $\begin{array}{l}17 \\
4.99(2 \cdot 19) \\
72 \cdot 4(2 \cdot 14) \\
(10 \cdot 9-258) \\
6 \cdot 19(2 \cdot 94) \\
1 \cdot 71(0 \cdot 86)\end{array}$ & $\begin{array}{l}19 \\
5 \cdot 88(3 \cdot 66)^{\star} \\
107 \cdot 1(2 \cdot 24)^{\star} \\
(30 \cdot 2-987 \cdot 8) \\
6 \cdot 69(3 \cdot 64) \\
2 \cdot 75(2 \cdot 14)^{\star}\end{array}$ \\
\hline
\end{tabular}

${ }^{\star} \mathrm{p}<0.05$ by Bonferroni (Dunn) $t$ tests. Abbreviations as for table 1 .

The relation of these urinary indices with duration of exposure in years was examined in the two groups (table 2). As expected, years of exposure was highly and significantly correlated with age in both groups. It was interesting to note, however, that in the low exposure group, neither age nor years of exposure was significantly correlated with any of these urinary indices, whereas in the high exposure group, exposure-years was significantly correlated with urinary AMG, BMG, and NAG. It was also interesting to note that urinary AMG, BMG, and NAG concentrations were all significantly correlated with one another.

The magnitude of the differences in urinary indices by both intensity and duration of exposure was further examined (table 3). Subjects who were exposed to high dust concentrations for 10 or more years clearly showed the most significant increase in urinary concentrations of AMG, BMG, and NAG. Subjects with less than 10 years of heavy exposure generally also had higher concentrations of these proteins and enzyme than workers in the low exposure group, although the differences were not statistically significant.

Further analyses involved the examination of the relation between exposure and radiological pneumoconiosis on the one hand and concentrations of urinary proteins and enzymes on the other. In this analysis, the subjects were further divided into three groups: a low exposure group with no radiological pneumoconiosis (mean (SD) age $32 \cdot 2(5 \cdot 2)$, exposure duration $8 \cdot 3(4 \cdot 7)$ years); a high exposure group with no radiological pneumoconiosis (mean (SD) age $33.4(9 \cdot 1)$, exposure duration $9.6(8.2)$ years); and a group with radiological pneumoconiosis (mean (SD) age $44 \cdot 2(11 \cdot 7)$, exposure duration $18.6(11 \cdot 2)$ years) (figure). Those with pneumoconiosis included five with irregular small opacities, denoting "mixed dust fibrosis" (mean (SD) age $38.2(13.2)$, exposure duration $13.2(6.4)$ years), and seven with rounded small opacities, denoting "classical silicosis" (mean (SD) age 46.6 (9.3), exposure duration $22.4(12 \cdot 8)$ years), all in radiological profusion categories $1 / 0$ to $1 / 2$. The results showed the highest increases in urinary concentrations of AMG $(p<0.01)$, BMG $(P<0.01)$, and
NAG $(p<0.01)$ in the group with radiological evidence of pulmonary fibrosis. It is interesting to note that low molecular weight proteinuria and enzymuria were more pronounced for those with classical silicosis compared with those with mixed dust fibrosis.

\section{Discussion}

The urinary excretion of high and low molecular weight proteins and enzymes are recognised to be useful markers of early glomerular and tubular dysfunction, and are highly sensitive tools for screening of industrial nephrotoxicity. ${ }^{11}$ The measurement of urinary BMG is a widely used test of early renal tubular deficiency, but its drawbacks are well known. It is easily degradable at urinary $\mathrm{pH}$ below 5.5, and this degradation starts in the bladder. For these reasons, special measures were taken to ensure optimal $\mathrm{pH}$ conditions of urine specimens before analyses. It was hence reassuring to note that the urinary BMG values were significantly correlated with that of another low molecular weight protein, AMG. $a-1-$ Microglobulin is a new indicator protein that has proved useful for the early detection of renal tubular dysfunction caused by environmental exposure to cadmium, ${ }^{12-14}$ and which also possesses the distinct advantage of being stable at urinary $\mathrm{pH}$ between 4 and 10 . Both low molecular weight proteinuria were correlated with urinary excretion of NAG, and these altogether provide strong assurance of the self-consistency and validity of these indices of renal tubular function.

The results of the present study confirmed previous findings of a nephrotoxic effect associated with long term occupational exposure in granite workers. Also, the additional information in this study provided further elucidation of the exposure effect relation. Clear evidence of renal tubular dysfunction was found in workers with 10 or more years of heavy exposure. These functional changes hence arise from prolonged and heavy exposure to dust, and as suggested by the results of our previous study of silicotic patients who had ceased exposure for many years may reflect irreversible 

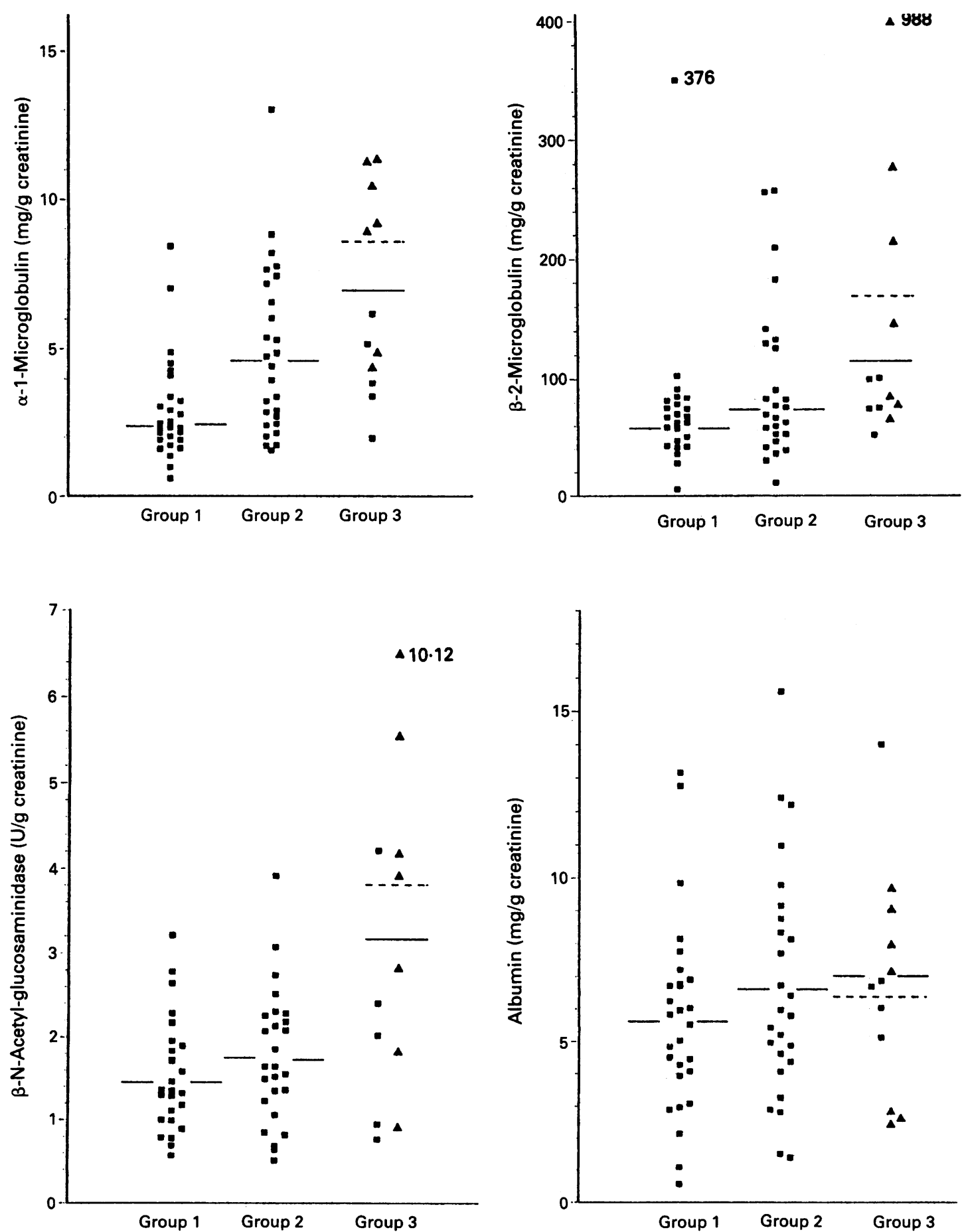

Urinary indices in low and high exposure and pneumoconiosis groups. Group $1(n=28)$ : low exposure, no radiological opacities. Group $2(n=27)$ : high exposure, no radiological opacities. Group $3(n=12)$ : radiological opacities with profusion $>=1 / 0$. Solid bar denotes arithmetic mean except for BMG (geometric mean). Dashed bar denotes mean for subjects with classical silicosis (closed triangles). 
damage. The urinary results in those with low dust exposure seemed to be normal, as they were essentially similar to the levels in the group of healthy subjects with no dust exposure in the previous study.

In our previous study, urinary excretion of albumin was significantly increased in subjects with heavy exposure to silica. In the present study, however, we were not able to replicate these results. Nevertheless, the possibility of glomerular disturbance cannot be excluded. Among other things, this might be due to differences in the characteristics of the subjects who were selected in the two studies. The highly exposed group of drilling and crushing workers in the present study were exposed for an average of 12 years, whereas the mean duration of exposure for a similar group of workers in the previous study was 16 years. The previous study also included more cases with greater severity of silicosis. It is possible that glomerular dysfunction might be evident subsequent to renal tubular disorder.

The possibility of unrecognised renal diseases of known pathology may be considered as an alternative explanation for the results. Urinary calculi were thought to be common among these granite workers because they performed strenuous work under an extremely hot outdoor environment, and it is possible that symptom free urinary calculi might explain these results. A systematic examination of the prevalence of known passage of urinary calculi in a larger group of these workers, however, did not suggest that those who were more heavily exposed to silica had higher risks than those less exposed. ${ }^{15}$

It is also possible that the urinary alterations in highly exposed workers might be explained by other potential nephrotoxic agents apart from silica in the granite quarrying work environment. Such exposures possibly include diesel and other petroleum based oils and lubricants, commonly used on machines and vehicles. In the low exposure group, loader operators and truck drivers, as well as some machine mechanics were in fact likely to be equally or more heavily exposed to these industrial substances than rock drillers or crusher workers. A thorough evaluation of environmental exposures in the granite industry that pose nephrotoxic hazards is made difficult by the present limited knowledge of the potential human nephrotoxicity of many industrial substances in use today. On the other hand, it is interesting to note the presence of low molecular weight proteinuria and enzymuria in subjects with radiological evidence of pulmonary fibrosis, which was most pronounced in those with classical silicosis, by contrast with subjects with mixed dust fibrosis. This finding favours an association with exposure to quarry dust, and as a high fractional content of free silica is typically associ- ated with classical silicosis, points at the same time towards a specificity for silica.

Although there are epidemiological studies of mortality in cohorts of workers exposed to silica, only a few reports provided data on deaths due to renal diseases, probably because of the few cases found. In our own cohort of 2000 silicotic subjects, we have also found only two deaths (expected 4.07) from genitourinary causes. ${ }^{16} \mathrm{~A}$ proportionate mortality study of Vermont granite workers ${ }^{17}$ found no statistically significant excesses of deaths overall from genitourinary causes (15 observed, 13.3 expected), but an excess of genitourinary disease (five observed, 1.8 expected) was noted in a subgroup of other quarry workers. A cohort study of Finnish granite workers ${ }^{18}$ found four cases of diseases of the urinary tract $(1.8$ expected), three of which were pyelonephritis (expected $0 \cdot 6$ ), and one chronic nephritis. Five other cases of renal disease were reported as contributing causes of death.

We conclude that prolonged heavy exposure to silica in granite workers is nephrotoxic, but, the clinical significance of these functional changes is still unclear. The risks of clinically or pathologically evident renal disease in persons exposed to silica should be actively investigated in future studies.

We thank Miss $\mathrm{Ng}$ Yuen Ling for her assistance with the laboratory analysis in this study.

Requests for reprints to: $\mathrm{Dr} \mathrm{T} \mathrm{P} \mathrm{Ng}$, Department of Community, Occupational, and Family Medicine, National University of Singapore, Lower Kent Ridge, Singapore 0511.

1 Saita G, Zavagilia O. La funzionalita renale nei silicotici. Med Lav 1951;42:41-8.

2 Capezzuto A. La funzionalita renale nei silicoti. Folia Med 1963;46:679.

3 Kolev K, Doitschinor D, Todorov D. Morphological alterations in the kidneys by silicosis. Med Lav 1970;61:205-10.

4 Saldana LF, Rosen VJ, Gonick HC. Silicon nephropathy. Am f Med 1975;59:95-103.

5 Giles RD, Sturgill BC, Suratt PM, Bolton WK. Massive proteinuria and acute renal failure in a patient with acute silicoproteinosis. Am $\mathscr{f}$ Med 1978;64:336-42.

6 Hauglustaine D, Van Damme B, Michielsen P. Silicon nephropathy: a possible occupational hazard. Nephron 1980;26:219-24.

7 Bolton WK, Suratt PM, Sturgill BC. Rapidly progressive silicon nephropathy. Am ₹ Med 1981;71:823-8.

8 Sherson D, Jorgensen F. Rapidly progressive crescenteric glomerulonephritis in a sandblaster with silicosis. $\mathrm{Br} \mathscr{f}$ Ind Med 1989;46:675-6.

$9 \mathrm{Ng} \mathrm{TP}, \mathrm{Ng}$ YL, Lee HS, Chia KS, Ong HY. A study of silica nephrotoxicity in exposed silicotic and non-silicotic workers. Br F Ind Med 1992;49:35-7.

$10 \mathrm{Ng}$ TP, Phoon WH, Lee HS, Ng YL, Tan KT. An epidemiological survey of respiratory morbidity among granite quarry workers in Singapore: radiological abnormalities. Ann Acad Med Singapore 1992;21:305-11.

11 Lauwerys RR, Bernard A. Early detection of the nephrotoxic effects of industrial chemicals: state of the art and future prospects. Am $\mathcal{F}$ Ind Med 1987;11:275-85. 
$12 \mathrm{Yu}$ H, Yanagisawa Y, Forbes MA, Cooper EH, Crockson RA, MacLennan ICM. Alpha-1-microglobulin: an indicator protein for renal tubular function. F Clin Pathol 1983;36:253-9.

13 Kido $T$, Honda $R$, Yamada $Y$, Tsuritani I, Ashizaki $M$, Nogawa K. Al-microglobulin determination in urine for the early detection of renal tubular dysfunctions caused by exposure to cadmium. Toxicol Lett 1985;24:195-201.

14 Tohyama C, Kobayashi E, Saito H, Sugihara N, Nakano A Mitane Y. Urinary al-microglobulin as an indicator protein of renal tubular dysfunction caused by environmental cadmium exposure. $\mathcal{f}$ Appl Toxicol 1986;6:171-8.

$15 \mathrm{Ng} \mathrm{TP}, \mathrm{Ng}$ YL, Lee HS. Dehydration from outdoor work and urinary stones in a tropical environment. Occup Med 1992;42:30-2.

$16 \mathrm{Ng}$ TP, Chan SL, Lee J. Predictors of mortality in silicosis. Respir Med 1992;86:115-9.

17 Davies LK, Wegman DH, Monson RR, Froines J. Mortality experience of Vermont granite workers. Am $\mathcal{f}$ Ind Med 1983;4:705-23.

18 Koskela RS, Klockars M, Jarvinen E, Kolari PJ, Rossi A. Mortality and disability among granite workers. Scand $\mathcal{f}$ Work Environ Health 1987;13:18-25.

Accepted 14 December 1992

\section{政}

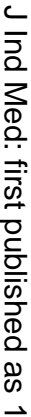

